\title{
Combat Exposure and Peritraumatic Factors Predicting PTSD among Military Personnel Fighting Insurgency in Nigeria
}

\author{
${\text { James } \text { Abel }^{1 *} \text {, Fredrick Sonter Anongo }}^{2}$, Binan Evans Dami ${ }^{3}$, Aboh James Ogbole ${ }^{4}$, Atsibi Abel ${ }^{3}$ and \\ Zubairu Kwambo Dagona ${ }^{1}$ \\ ${ }^{1}$ Headquarters, Theatre Command, Op LAFIYA DOLE, Kinnasara Barracks Mongonu Maiduguri Borno State, Nigeria \\ ${ }^{2}$ Department of Psychology, Faculty of Social Sciences, University of Ibadan, Nigeria \\ ${ }^{3}$ Mental Health and Psychosocial Support Officer, International organization for Migration, Banjul, Gambia \\ ${ }^{4}$ Headquarters, Theatre Command, psychological services centre Operation LAFIYA DOLE, Maimalari Cantonment \\ Maiduguri
}

"Corresponding author: Abel J, Headquarters, Theatre Command, Op LAFIYA DOLE, Kinnasara Barracks Mongonu Maiduguri Borno State, Nigeria, Tel: +2348038090211; E-mail: abeljames14.aj@gmail.com

Received: November 16, 2018; Accepted: December 02, 2018; Published: December 05, 2018

\begin{abstract}
Previous studies indicate that posttraumatic stress disorder is one of the major mental health challenges that affect military personnel who have experienced combat situations. However, there is still paucity of research on the factors that predict PTSD in Nigerian military setting despite increasing rate of Boko-Haram exposure. This study therefore examined the predictive influence of peritraumatic factors (combat exposure, number of deployments, duration of deployments and substance use) among Nigerian military personnel exposed to Boko-Haram insurgency in North-eastern Nigeria. Data were collected using standardized questionnaires on a sample of 715 participants. Two hypotheses were tested using Pearson correlation and hierarchical multiple regression, and results revealed a significant positive relationship between combat exposure $(r=.36 ; p<.05)$, substance use coping $(r=.14 ; p<.01)$ and PTSD. However, number $(r=.07 ; p>.05)$ and duration of deployments $(r=.04 ; p>.05)$ were found to have no significant relationship with PTSD. Additional findings indicated that combat exposure $(\beta=.32, t=9.10 ; p<.05)$ and using substance to cope with the experience of $\operatorname{combat}(\beta=-.11, t=-3.14 ; p<.05)$ independently and jointly $\left[\mathrm{R}^{2}=.36, \mathrm{~F}(4,707)=15.13, \mathrm{P}<.05\right]$ predicted PTSD, while the influence of duration and multiple deployments were statistically insignificant. Findings imply that Nigerian military personnel who experience combat and resort to substance use to cope stand a higher risk of developing PTSD. Thus, Military authority should give adequate attention on training to restrain its personnel from substance use coping during stressful encounters to prevent the development of posttraumatic stress disorder.
\end{abstract}

Keywords: Combat exposure; Boko-Haram; PTSD

Citation: Abel J, Anongo FS, Dami BE, et al. Combat Exposure and Peritraumatic Factors Predicting PTSD among Military Personnel Fighting Insurgency in Nigeria. J Anxiety Depress. 2018;1(2):108. 
www.yumedtext.com | December-2018

\section{Introduction}

Globally, posttraumatic stress disorder has long been recognized as one of the major mental health problems that affect people with different forms of traumatic experiences- rape, accident, community violence, and natural disasters. However, this condition appears to be more common and highly prevalent among war victims, especially military personnel exposed to combat situations [1-4]. This is not surprising because, the term itself was first noticed after military engagement in the first and second world wars, and became even more popular when the American/Vietnam veterans returned from the war front and serious distress was noticed by their families and community members [1]. In recent engagement named "operation desert storm" in Iraq and Afghanistan, PTSD became a serious psychological problem among military personnel who participated in the operation. The general prevalence rate for this population was found to range between $10 \%-17 \%$ [5]. In recent studies, higher prevalence of $33 \%$ has been reported in African setting on a study involving south-African military personnel [4].

In line with APA [6], defined posttraumatic stress disorder as a psychiatric condition that occurs after witnessing or experiencing an event that is traumatic to which one responds with intense fear, apprehension or horror. Similarly the latest version of diagnostic and statistical manual of mental disorders [7], describes PTSD as a "trauma stress -related" disorder resulting from exposure or witnessing of a potentially traumatic event such as actual or threatened death, exposure to accidents, natural disasters, combat events, etc., with symptom clusters of re-experiencing, avoidance, hyperarousal, negative alteration in cognition and mood. This definition clearly suggests that having experience of war trauma could increase PTSD vulnerability. This raises a serious concern on our military organization and its personnel considering the level of combat exposure they have had in recent times. The recent engagement of the Nigerian armed forces with the Boko Haram insurgents have produced residual combat stress that could result in PTSD. Many of these personnel were exposed to potentially traumatic combat experiences such as watching the death of their colleagues, exposure to high improvised explosives, harsh weather, hostile incoming fire, mass burial of colleagues among others. This coupled with frequent stay and long duration of deployment could add significantly to the psychological distress symptoms suffered by Nigerian armed forces. For instance, in previous studies among the population, [8] identified posttraumatic stress disorder as one of the major psychological wounds of war that have inflicted military personnel who participated in Operation Lafia Dole in North East Nigeria. A positive relationship was later found between combat exposure and posttraumatic stress disorder in the same population [9]. To this end [10], asserted that the experience of Nigerian military with Boko-Haram is a serious menace that must be examined regularly to identify emerging perspectives that could, in addition to the combat event, contribute the development of this condition so that appropriate and timely psychological intervention can be instituted.

Troops in the operational theatre and those that have recently returned from the North East have become a social menace to the military barracks communities. They have apparently displayed impairment in social and occupational functioning characterized by high substance use as there have been an observed corresponding increase in the abuse of psychoactive substances in military barracks. In addition, increases in marital conflicts, lack of motivation with attendant negative impact on productivity and efficiency to assigned duties have been reported. This has further corroborated some previous findings revealing the deleterious effects of PTSD among military veterans including increased marital and social problems, suicidal thoughts, respiratory and gastrointestinal problems and higher cortisol [11,12] poor productivity, lack of commitment, high financial burden of mental health care and even early retirement in deployed military officers [13-15], cognitive impairments, 
www.yumedtext.com | December-2018

suicide, reduced physical health, increased engagement in unhealthy behaviours, substance abuse, unemployment, poor performance while at work, homelessness, marital strain, domestic violence and poor parent-child relationships in military personnel [16].

However, beyond the impact of trauma, research has also shown that the number of times people experience a traumatic situation is related to posttraumatic stress disorder. In this regard, people who have had multiple traumatic experiences are found to report more distressing symptoms than the less frequently encountered trauma population [17-18]. This means that the more frequent military personnel are deployed for combat operations, the greater the possibility that they will develop posttraumatic stress disorder. Thus, in a sample of operation Iraqi freedom, [19] found that the number of times deployed to a war zone was positively associated with posttraumatic stress disorder. The Boko-Harm operation was equally characterised by frequent deployment but not very much is known on the influence on this factor in PTSD.

In addition, existing studies have shown that the length of deployment is another factor that influence psychological adjustment in veterans deployed for war operations. In line with the Hans Seyle's theory of stress, many studies have shown that when military personnel have protracted stay at war zones, their ability to withstand the effect of the trauma becomes diminished opening the path to posttraumatic stress disorder. For example, Angkaw AC et al. [20] found that the longer duration of time spent in theatre was associated with an increased susceptibility to psychological problems and difficulties with home life after deployment. The implication of this is that having protracted stay at war zones increases more changes of posttraumatic stress disorder. Similarly, it was found among American veterans deployed for operation Iraqi freedom that at four months into a peacekeeping deployment, only $14.8 \%$ of members met the criteria for a diagnosis of depression, but at nine months, $21.6 \%$ were considered depressed [19]. This again has demonstrated that prolonged stay in combat battle affects a chain of psychological problems including posttraumatic stress disorder.

Beside the impact of combat-related factors, coping behaviours have been shown to influence mental health. In military population, substance use coping has been found to be highly prevalent. In fact, it has been revealed that $50 \%$ of men with PTSD also report alcohol abuse and that over 63\% of American veterans deployed to Iraq and Afghanistan with alcohol use met criteria for PTSD [21]. Thus, considering that a significant number of Nigerian military personnel indulge in one form of substance or the other during stress, it therefore suggests that this variable may have an influence on PTSD. Previous studies have shown that using substances like alcohol exacerbates posttraumatic stress disorder by reducing concentration and increasing emotional numbing, social isolation, irritability, anger and the feeling of needing to be on guard [21]. It has also been revealed that there is a strong relationship between alcohol and arousal symptoms and that alcohol withdrawal may sometimes induce flashback symptoms of posttraumatic stress disorder [22].

However, there are still ambivalent results regarding substance use and PTSD. While some studies have associated alcohol and cannabis use with increased PTSD severity [23], recent reports from meta-analyses have found that substance use is not positively related to PTSD [24].This gives room for further investigation especially in Nigerian clime where substance use has become a common coping method among deployed military personnel. 
www.yumedtext.com | December-2018

\section{Statement of Problem}

From the foregoing, it is obvious that PTSD has been an existential problem among military personnel since its first discovery after the First World War. However, this is becoming a more serious challenge as emerging studies have shown a steady increase its prevalence with corresponding consequences [26,27]. In Nigeria for instance, recent empirical findings have revealed that three out of ten (3/10) combat military personnel is vulnerable to PTSD [16]. This appears disturbing as security challenges orchestrated by Boko-Haram Insurgent have forced combat deployment on the apparently ill prepared and poorly equipped military population in recent times. In order to contain the Boko-Haram menace, many of the Nigerian military personnel were deployed to the war front. In the course of this exposure, many military personnel and other security agencies were exposed to combat stress, in the theatre of war, such as being wounded due to improvise explosive device (IED), enemy action, friendly firing, self-inflicted injury, and deliberate self-harm and trauma cases caused by non-enemy actions. Some of the army personnel whether physically injured or not have resorted to use of substances to escape or suppress the trauma (FGD, 2018) and sadly, this form of coping with trauma has been shown to increase vulnerability to PTSD in foreign studies.

Apart from the deployment, many of the soldiers were subjected to frequent postings while others had protracted deployment without rotation. In the past, these variables have demonstrated to affect metal health. According to Fear and Jones [28], deployment length can negatively affect mental health status, morale, and relationships with family and friends. In addition, longer deployments are often cited as reasons for personnel to leave their location of deployment without leave or pass and general decline in mental health condition [27]. This is in addition to other observable psycho-social consequences such as poor motivation, reduced commitment and suicidal thoughts that might ravage the force if timely investigation and intervention is not initiated. Surprisingly, there is no documented research on the role of contextual factors and most importantly, coping behaviour in PTSD in Nigeria military population. Previous studies [16,10] that have attempted to unravel the risk factors to combat-related PTSD are limited to demographic factors and with more emphasis on hospitalized population. This has denied us understanding on the influence of some important contextual factors like number of deployments, duration of deployments and substance use coping that has very serious implication on PTSD among veterans. This knowledge is important because using certain strategies like substance to cope could affect trauma outcome in line with the self-medication hypothesis [29]. These are obvious research gaps that prompted this study. In response to the gaps, the study therefore brought out two basic objectives: (1) to investigate if there is any significant association between combat exposure, number of deployment, duration of deployments, substance use coping and posttraumatic stress disorder; (2) to examine if combat exposure, number of deployments, duration of deployments and substance use coping will significantly independently and jointly predict PTSD among Nigerian military personnel exposed to Boko-Haram insurgency in the north eastern Nigeria.

\section{Hypotheses}

1. There will be a significant relationship between combat exposure, number of deployments, duration of deployments, substance use coping and posttraumatic stress disorder among military personnel exposed to Boko-Haram Insurgency. 
www.yumedtext.com | December-2018

2. Combat exposure, multiple deployments and duration of deployment will significantly independently and jointly predict posttraumatic stress disorder among military personnel exposed to Boko-Haram insurgency.

\section{Method}

A cross-sectional survey design was adopted to elicit information from seven hundred and fifteen (715) Nigerian Army personnel deployed to combat Boko-Haram insurgents in the North East. Eligible participants were recruited majorly from Borno state using purposive sampling method. Their age range was from 18-60 and comprised majorly male combatants. Demographic characteristics of the participants revealed that a total of 271 (37.9\%), fall within the age range of 20-30 years; $243(34 \%)$ 31-40 years; 182 (25.5\%), 41-50 years while a total of 19 participants (2.7\%) were above 50 years. On sex, 710 $(99.3 \%)$ were male soldiers while a total of $5(.7 \%)$ were female participants. Information on participants' religious affiliation show that 447 (62.5\%) were Christians, while 268 (37.5\%) were of Islamic religion. Regarding marital status, a total of 555 $(77.5 \%)$ are married, $9(1.3 \%)$ are currently divorced, while $152(21.3 \%)$ are still single. Concerning participants' rank, 129 (20.8\%) are private, $153(21.4 \%)$ Lance corporal, 174 (24.3) corporal, 110 (15.4) sergeant, staff sergeant 65 (9.1\%), warrant officer $22(3.1 \%)$, Lieutenant $18(2.5 \%)$, Captain $16(2.2 \%)$, Major $6(.8 \%)$ while a total of $2(.3 \%)$ participants were military colonels.

\subsection{Measures}

\subsubsection{Demographic and peritraumatic characteristics}

Demographic and contextual information bothering on age, marital status, rank, job experience, religious affiliation, and educational qualification, level of substance use, number and duration of deployments were gathered from the participants using simple questions that tapped relevant information on those items.

\subsubsection{Combat exposure scale (CES)}

The Combat Exposure Scale (CES) is a 7-item self-report measure that assesses wartime stressors experienced by combatants. Items are rated on a 5-point frequency $(1=$ "no" or "never" to $5=$ "more than 50 times"), 5-point duration $(1=$ "never" to 5 = "more than 6 months"), 4 point frequency ( $1=$ "no" to 4 = "more than 12 times") or 4-point degree of loss $(1$ $=$ "no one" to $4=$ "more than $50 \%$ ) scale. Respondents were asked to respond based on their exposure to various combat situations, such as firing rounds at the enemy and being on dangerous duty. The total CES score is calculated by using a sum of weighted scores, which can be classified into 1 of 5 categories of combat exposure ranging from "light" to "heavy." The CES was developed to be easily administered and scored and is useful in both research and clinical settings. The total exposure to combat score can be categorized according to the following scale: 0-8 light, 9-16 light - moderate, 17-24 moderate, 25-32 moderate - heavy, and 33-41 heavy [30]. The mean score on the Combat Exposure Scale was 25.57 (SD = 10.12); scores ranged from 1 to 41. Coefficient alpha was calculated and yielded a value of .85. This high degree of reliability indicates that the items are measuring the same or a very similar construct. As a second measure of internal consistency, the average correlation was .75 (range $=.64$ to .83 ). Test-retest reliability with a 1 -week interval was calculated for all three groups combined, $\mathrm{r}(29)=.97, \mathrm{p}<.0001$. There were no between-group differences in the test-retest correlations. The means for Time I and Time 2 were 23.2 and 22.2, respectively, indicating excellent stability over this time period [30]. 
www.yumedtext.com | December-2018

\subsubsection{Substance use coping}

Substance use coping was measured using the substance use subscale of the multidimensional coping inventory [27]. Basically, the scale comprises 15 conceptually different dimensions of coping that assess a variety of coping strategies in which individuals may adopt under stressful conditions. However, only substance use dimension was adopted due to its applicability in the present study. The substance use coping dimension consists of four items in which respondents are asked to indicate how much they have used substance in the past month in relation to trauma using a four-point scale $(1=\mathrm{I}$ haven't been doing this at all; $2=$ I've been doing this a little bit; $3=$ I've been doing this a medium amount; $4=$ I've been doing this a lot) Sample questions include:" I have been using alcohol or other drugs to make myself feel better", "I have been using drugs or alcohol in order to think less about the problem". Psychometrically, Carver CS et al. [34] reported a sound cronbach's alpha $(\alpha=.73)$, and in the present study, a cross-validation revealed even a higher cronbach's alpha $(\alpha=.80)$ demonstrating an excellent reliability and a sound measure in Military population in Nigeria. The mean and standard deviation for the dimension was found at $(\pi=11.80, \mathrm{SD}=3.00)$. High scores at or above the mean indicate high use of substance use coping and vice versa.

\subsubsection{Posttraumatic stress disorder checklist-military}

(PCL-M) is a self-report rating scale that measures PTSD symptom severity in military veterans [31]. The PCL-M is a 17item self-report questionnaire. The scale is scored by calculating a total score. This score is derived by adding the responses to all scale items. The total score may range from 17 to 85, where elevated scores suggest greater severity. Ratings are chosen according to how much the veteran has been disturbed by a particular traumatic military-related incident. The scale has proven useful with both male and female veteran populations [31]. This scale has been shown to be both valid and reliable ( $\alpha$ $=.96$ ) in previous research $[32,33]$. The internal reliability for the sample used in the current study was .96. The PCLM was scored by adding up all the items for a total severity score. A total score of 50 was considered to be PTSD positive in military populations [31-33] found that overall diagnostic efficiency was improved to 0.900 when the cutoff score was lowered to 44, yielding a sensitivity of 0.944 and specificity of 0.864 and correctly identifying 17 of 18 participants with PTSD. In this present study the cutoff score of 44 recommended by [33] is adopted as cutoff.

\section{Procedure}

Upon obtaining necessary permission/approval from the military authorities, the researcher engaged some research assistants, who were properly given orientation on the instruments and procedure for data collection. They were taught on how to administer the instruments and encourage participants to complete the questionnaire correctly under the supervision of a uniform psychologist deployed with the soldiers. After adhering to the necessary ethical standards, the researchers distributed a total of 750 standardized questionnaires to participants who met inclusion criteria for participation. However, 35 were discarded due to improper completion. Therefore, 715 sets of the inventories were used for analysis. The non-probability (purposive) sampling technique was applied to select the participants from different deployment locations in the theatre of operation Lafiya Dole. The questionnaire is self-administered, so it was distributed to the soldiers to fill and afterwards, retrieved for data analysis. 
www.yumedtext.com | December-2018

\section{Ethical Consideration}

Permission to conduct the study was sought and granted by the theatre commander Operation Lafiya Dole. However, before participants took part in the study, their consent was duly sought to ensure that their participation was by free will and once this consent was given by filling a written consent form the researcher assured them of strict confidentiality of the information so provided. This promise was kept in earnest. The researchers also ensured that only relevant information pertaining the study were collected through the questionnaire in order to avoid unnecessary invasion of privacy. On the issue of risk, he ensured that no participant was meant to incur any physical risk. However, the possibility of minimal economic and social risk, such as stigma and impact on career prospects made him strictly adhered to the principle of confidentiality. No name or any obvious means of identification was required, except for the phone numbers, which provided direction for identifying participants for the intervention.

More so, participation for the study required no cost and was voluntary as he assured them that they had the right to withdraw participation at any time they so desired. On research benefits, the researchers offered some health talks and assured them that the research findings would be implemented to improve their health and welfare.

\section{Data Analysis}

Statistical package for social sciences (SPSS-version-20) was employed as a statistical tool to analyse the study hypotheses. Hypothesis one was analysed using Pearson $r$ correlation statistics, which helped established relationships between combat exposure, number of deployments, duration of deployment, substance use and PTSD. Hierarchical multiple regression was used to test hypothesis two, which sought for the independent and joint influences of combat exposure, number of deployments, duration of deployments and substance use coping on posttraumatic stress disorder among the studied sample.

\section{Results}

TABLE 1. Summary of a Zero-Order Correlation Showing Relationship between Combat Exposure, Duration of Deployments, Number of Deployments, Substance use coping and PTSD.

\begin{tabular}{|c|c|c|c|c|c|c|c|}
\hline Variables & $\mathbf{X}$ & SD & $\mathbf{1}$ & $\mathbf{2}$ & $\mathbf{3}$ & $\mathbf{4}$ & $\mathbf{5}$ \\
\hline Combat exposure & 19.65 & 7.33 & - & & & \\
\hline Duration of Deployments & 2.82 & 1.54 & $.10^{* *}$ & - & & \\
\hline Number of Deployments & 2.61 & 7.89 & .02. & 03 & - & & \\
\hline Substance use coping & 5.89 & 2.17. & $08^{*}$ & .05 & -.04 & - & \\
\hline PTSD & 35.99 & 16.92. & $36^{* *}$ & .07 & .04 & $.14^{* *}$ & - \\
\hline
\end{tabular}

Results on TABLE 1 presented above represents findings on hypothesis one. From the table, it reveals that there is a significant positive relationship between combat exposure $(r=.36 ; \mathrm{p}<.05)$, substance use coping $(\mathrm{r}=.14 ; \mathrm{p}<.01)$ and PTSD. There was no found statistical relationship between duration of deployments $(\mathrm{r}=.07 ; \mathrm{p}>.05)$, number of deployments $(\mathrm{r}=.04$; p>.05) and posttraumatic stress disorder. 
TABLE 2. Summary of Hierarchical Multiple Regression Analysis Showing the Predictive impact of Combat exposure and peritraumatic factors on Posttraumatic Stress Disorder among Nigerian Military Personnel Exposed to

Insurgency.

\begin{tabular}{|c|c|c|c|c|c|c|c|c|}
\hline Predictors & $\boldsymbol{\beta}$ & $\mathbf{t}$ & $\mathbf{P}$ & $\mathbf{R}$ & $\Delta \mathbf{R}^{2}$ & $\mathbf{R}^{2}$ & $\mathbf{F}$ & $\mathbf{P}$ \\
\hline Age & -0.1 & 2.19 & $<.05$ & & & & & \\
\hline Rank & -0.01 & -0.29 & $>.05$ & & & & & \\
\hline Marital status & 0.03 & .78 & $>.05$ & 0.09 & 0.01 & .01 & 1.92 & $>.05$ \\
\hline Age & 0.09 & 1.38 & $>.05$ & & & & & \\
\hline Combat exposure & 0.32 & 9.1 & $<.01$ & & & & & \\
\hline Duration of deployments & -0.03 & -0.41 & $>.05$ & 0.12 & 0.13 & .36 & 15.13 & $<.05$ \\
\hline Number of deployments & 0.02 & 0.59 & $>.05$ & & & & & \\
\hline Substance use coping & -0.11 & -3.14 & $<.05$ & & & & & \\
\hline
\end{tabular}

$* * \mathrm{p}<.01, * \mathrm{p}<.05$

TABLE 2 presents results on hypothesis two, on the predictive influences of peritraumatic factors (combat exposure, number of deployments, duration of deployments and substance use coping) on PTSD after statistically controlling for extraneous factors. Thus, in the first model of hierarchical regression analysis, the control variables of rank $(\beta=-.01, \mathrm{t}=-.29 ; p>.05)$, marital status $(\beta=.03, \mathrm{t}=.78 ; p>.05)$ had no significant independent nor joint influence $\left[\mathrm{F}_{(3,711)}=1.92 ; \mathrm{R}^{2}=.01 ; \mathrm{p}>.05\right]$ on PTSD except age of the personnel $(\beta=-0.1, \mathrm{t}=2.19 ; p<.05)$, which emerged as an independent predictor. However, with the introduction of peritraumatic factors in the second model, the influence of age $(\beta=-.09, \mathrm{t}=1.38 ; p>.05)$ on PTSD was no longer significant. Rather, the peritraumatic factors of combat exposure $(\beta=.32, \mathrm{t}=9.10 ; p<.05)$ and substance use coping $(\beta=-.11, \mathrm{t}=-3.14 ; p<.05)$ emerged as independent predictors of PTSD, while the result for duration $(\beta=-.03, \mathrm{t}=-.41 ; \mathrm{p}>.05)$ and number of deployments was statistically insignificant $(\beta=.02, \mathrm{t}=.59 ; p>.05)$. Altogether, the four peritraumatic variables had a joint predictive impact $\left[\mathrm{R}^{2}=.36, \mathrm{~F}(4,707)=15.13, \mathrm{P}<.05\right]$, accounting for a significant change of $3.6 \%$ in the variance of PTSD.

\section{Discussion}

The purpose of this study was to explore how combat exposure and some peritraumatic factors (Number of deployments, duration of deployments, substance use) would predict posttraumatic stress disorder among a sample of Nigerian military personnel exposed to Boko-Haram Insurgency. In line with the stress response theory and self-medication hypothesis, result testing hypothesis one revealed a significant positive relationship between combat exposure $(r=.36 ; p<.05)$, substance use coping $(r=.14 ; \mathrm{p}<.01)$ and PTSD. There was no found statistical relationship between duration of deployments $(r=.07$; $\mathrm{p}>.05)$, number of deployments $(r=.04 ; \mathrm{p}>.05)$ and posttraumatic stress disorder. This implies that the number of times or duration of stay in the theatre is inconsequential to increasing PTSD; rather an increase in the level of combat exposure itself and use of substances to cope with the exposure will result in a consequent increase in level of posttraumatic stress disorder reported by the military personnel. This result is somewhat consistent with previous studies as seen in [23,24] who in their separate studies found combat exposure and substance use as positive correlates of posttraumatic stress disorder. This therefore means that the more highly intense military personnel experience combat events and the more they employ substances to manage such situations, the greater they will experience PTSD. With regards to the non-significant relationship between number of deployments and duration on PTSD, this study appeared inconsistent with [19] which found a significant 
www.yumedtext.com | December-2018

positive association between duration and lengths of deployments and posttraumatic stress disorder. Specifically, it was reported that American veterans deployed for operation Iraqi freedom endorsed less psychological problems (depression) at four months $(14.8 \%)$ than at nine months $(21.6 \%)$ of deployment.

In addition, findings on TABLE 2 testing hypothesis two, on the predictive impact of the peritraumatic factors on PTSD revealed that, in the first model of hierarchical regression analysis, the control variables of rank $(\beta=-.01, \mathrm{t}=-.29 ; p>.05)$, marital status $(\beta=.03, \mathrm{t}=.78 ; p>.05)$ had no significant independent nor joint influence $\left[\mathrm{F}_{(3,711)}=1.92 ; \mathrm{R}^{2}=.01 ; \mathrm{p}>.05\right]$ on PTSD except age of the personnel $(\beta=-0.1, \mathrm{t}=2.19 ; p<.05)$, which emerged as an independent predictor. However, with the introduction of peritraumatic factors in the second model, the influence of age $(\beta=-.09, \mathrm{t}=1.38 ; p>.05)$ on PTSD was no longer significant. Rather, the contextual factors of combat exposure $(\beta=.32, \mathrm{t}=9.10 ; p<.05)$ and substance use coping ( $\beta=-$ $.11, \mathrm{t}=-3.14 ; p<.05)$ emerged as independent predictors of PTSD, while the result for duration $(\beta=-.03, \mathrm{t}=-.41 ; \mathrm{p}>.05)$ and number of deployments was statistically insignificant $(\beta=.02, \mathrm{t}=.59 ; p>.05)$. Altogether, the four peritraumatic variables had a joint predictive impact $\left[\mathrm{R}^{2}=.36, \mathrm{~F}(4,707)=15.13, \mathrm{P}<.05\right]$ and accounted for significant change of $3.6 \%$ in the variance of posttraumatic stress disorder in the population. This result indicates that the impact of other control variables like age, rank and marital status of the personnel (which previous studies have associated with PTSD) is not influential to PTSD in Nigerian military population. Rather, combat exposure and indulging in substance use to escape or suppress the trauma experienced at war zones is what has actually led to PTSD in the population. Additionally, frequent deployments and protracted stay are equally not important factors. The most important thing is the true experience of horrible combat events by the military personnel and the act of trying to repress same using substances that can significantly increase PTSD vulnerability in the officers and soldiers of the force. This result is supported by $[23,20,4,16,21]$ studies which found that combat exposure and substance use are significant predictors of PTSD in military population. It however, contradicts some findings [19, 24] which found no relationship between substance use and posttraumatic stress disorder in a military sample.

\section{Conclusion}

In line with the findings on hypothesis one that combat exposure and substance use coping have significant positive relationship with PTSD, this study has drawn conclusion that military personnel who experience combat events stand a high risk of developing posttraumatic stress disorder. Similarly, increased use of substances to manage or suppress these unpleasant combat experiences after homecoming could lead to more cases of PTSD in Nigerian military personnel.

In addition, drawing from findings on hypothesis two, which revealed a significant predictive impact of combat exposure and substance use coping on PTSD, the study concluded that exposure to combat and using avoidance techniques to handle the trauma upon return are significant risk factors to PTSD in combat veterans. Therefore, when military personnel are exposed to trauma, less attention should be given to how long they stay or how frequently they have been exposed to it; rather, their coping mechanisms should be explored to know if they are using substances to cope with the experience which might become counterproductive as shown in this study.

The study therefore recommended that military personnel who experience combat stress should be prevented from adopting substance use as a coping strategy as it has proven to exacerbate PTSD in this study. By the same token, appropriate stress management techniques should be taught, especially after exposure to stressful events that are potentially traumatic. 
Adequate attention should therefore be given to the role of peritraumatic factors to prevent post-deployment problems in Nigerian military population to ensure effective security of lives and property of the populace.

\section{REFERENCES}

1. Hoge CW, Castro CA, Messer SC, et al. Combat duty in Iraq and Afghanistan, mental health problems, and barriers to care. N Engl J Med. 2004;351(1):13-22.

2. Milliken CS, Auchterlonie JL, Hoge CW. Longitudinal assessment of mental health problems among active and reserve component soldiers returning from the Iraq war. JAMA. 2007;298(18): 2141-8.

3. Gates AM, Holowka DW, Vasterling JJ, et al. Posttraumatic stress disorder in veterans and military personnel: epidemiology, screening and case recognition. Psychol Serv. 2012;9(4):361-82.

4. Connell MA, Omole O, Subramaney U, et al. Posttraumatic stress disorder and resilience in veterans who served in the South African border war. Afr J Psychiatry. 2013;16(6).

5. Hoge CW, Terhakopian A, Castro CA, et al. Association of posttraumatic stress disorder with somatic symptoms, health care visits, and absenteeism among Iraq war veterans. Am J Psychiat. 2007;164(1):150-3.

6. Haigin RP, Whitourne SK. Abnormal psychology clinical perspectives on psychological disorders. 5th ed. Boston: McGraw-Hill, USA; 2007.

7. American Psychiatric Association. Diagnostic and statistical manual of mental disorders. 5th ed. Washington, DC: APA Publishing, USA; 2013.

8. Abel J, Dagona ZK, Omoruri OJ, et al. The wounds of Terrorism among combat Military personnel in Nigeria. J Psychol Clin Psychiatry. 2018;9(4):425-9.

9. Dami BE, James A, Zubairu D, et al. Combat exposure and PTSD among military combatants in North East Nigeria. J Psychol Clin Psychiatry.2018;9(4):400-4.

10. Dagona ZK. An assessment of Peace and conflict management institutions in Africa. Paper presented at the Confederation of Conflict Institutes in Nigeria. Seminar held at Abdulsalami Abubakar institute for Peace and Development Minna. Niger State; 2015 15-17 Nov.

11. Papazoglou K, Andersen JP. A Guide to utilizing police training as a tool to promote resilience and promote health outcomes among police officers. Traumatol: Int J. 2014;20(2):103-11.

12. Araujo AX, Berger W, Coutinho ES, et al. Comorbid depressive symptoms in treatment-seeking PTSD outpatients affect multiple domains of quality of life. Compr Psychiatry. 2014;55(1):56-63.

13. Kessler RC. Post-traumatic stress disorder: the burden to the individual and to society. J Clin Psychiatry. 2000;61(5):4-12.

14. Eibner C, Ringel JS, Kilmer B, et al. The Cost of Post-Deployment Mental Health and Cognitive Conditions. In: Tanielian T, Jaycox LH editors. Invisible Wounds of War: Psychological and Cognitive Injuries, their Consequences, and Services to Assist Recovery. Santa Monica: RAND, USA; 2008.

15. Pastwa-Wojciechowska B, Piotrowski A. Sources, consequences and methods of coping with stress in police officers. J Alcohol Drug Depend. 2016;4(4):244.

16. Ameh S, Kazeem T, Abdulkarim B, et al. Post-Traumatic Stress Disorder among Nigerian Military Personnel Findings from A Post Deployment Survey. Pro J Humanit Soc Sci. 2014;02(1):56-61. 
www.yumedtext.com | December-2018

17. Gabriella ES, Punamaki S. Traumatic events, PTSD and psychiatric co-morbodity in forensic patients : assessed by questionnaires and diagnostic interview. Clin Pract Epidemiol Ment Health. 2006; 2:1-7.

18. Kolassa IT, Kolassas S, Ertl V, et al. The Risk of Posttraumatic Stress Disorder After Trauma Depends on Traumatic Load and the Catechol-O-Methyltransferase Val158Met Polymorphism Bio1 Psychaitry. 2010;67(4):3048.

19. Adler A, Huffman A, Bliese P, et al. The impact of deployment length and experience on the well-being of male and female soldiers. J Occup Health Psychol. 2005;10(2):121-37.

20. Rona RJ, Fear NT, Hull L, et al. Mental health consequences of overstretch in the UK armed forces: First phase of a cohort study. BMJ. 2007;335(7620):603-10.

21. Angkaw AC, Haller M, Pittman OE, et al. Alcohol - related consequences mediating posttraumatic stress disorder symptoms and mental health-related quality of life in operation enduring freedom and operation Iraqi freedom veterans. Mil Med. 2015;180(6):670-5.

22. Ouimette P, Moos RH, Finney JW. Post-traumatic stress disorder treatment and 5-year remission among patients with substance use and posttraumatic stress disorders. J Consult Clin Psychol. 2003;71(2):410-14.

23. Okulate GT, Jones OBE. Post-traumatic stress disorder, survivor guilt and substance use - a study of hospitalized Nigerian army veterans. S Afr Med J. 2006;96(2):144-6.

24. Tackett DP. Resilience factors affecting the readjustment of National Guard soldiers returning from deployment. Dissertation and Thesis Submitted to Antioch University Santa Barbara Paper 119, 2011.

25. Galovski T, Lyons JA. Psychological sequelae of combat violence: A review of impact of combat violence on PTSD on veterans family and possible intervention. Aggression and Violent Behaviour. 2004;9(5):477-501.

26. Dai J, Yu H, Wu J, et al. Analysis on the association between job stress factors and depression symptoms. Wei Sheng Yan Jiu. 2010;39:342-6.

27. Cesur R, Sabia J, Tekin E. The psychological costs of war: Military combat and mental health. J Health Econ. 2013;32(1):51-65.

28. Fear NT, Jones MM. What are the consequences of deployment to Iraq and Afghanistan on the mental health of the UK armed forces? A cohort study. Lancet. 2010;375(9728):1783-97.

29. Khantzian E. The self-medication hypothesis of addiction disorders, focus on heroin and cocaine dependence. Am $\mathbf{J}$ Psychiatry. 1985;142(11):1259-64.

30. Keane TM, Fairbank JA, Caddell JM, et al. Clinical evaluation of a measure to assess combat exposure. Psychol Assess. 1989;1(1): 53-5.

31. Weathers FW, Huska JA, Keane TM. PCL-C for DSM-IV Boston: National Centre for PTSD- Behavioural Science Division, 1991.

32. Adler AB, Bliese PD, McGurk D, et al. Battle mind debriefing and battle mind training as early interventions with soldiers returning from Iraq: Randomization by platoon. J Consult Clin Psychol. 2009;77(5):928-40.

33. Pietrzak RH, Johnson DC, Goldstein MB, et al. Perceived stigma and barriers to mental health care utilization among OEF-OIF veterans. Psychiatr Serv. 2009;60(8):1118-22.

34. Carver CS, Scheier MF, Weintraub JK. Assessing coping strategies: a theoretically based approach. J Pers Soc Psychol. 1989;56(2):267-83. 